The opportunities and challenges of mobile and ubiquitous learning for future schools: A context of Thailand

Patcharin Panjaburee

Mahidol University, Thailand

Niwat Srisawasdi

Khon Kaen University, Thailand

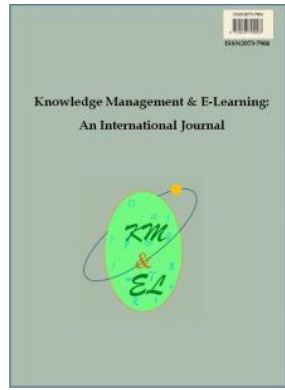

Knowledge Management \& E-Learning: An International Journal (KM\&EL) ISSN 2073-7904

Recommended citation:

Panjaburee, P., \& Srisawasdi, N. (2018). The opportunities and challenges of mobile and ubiquitous learning for future schools: A context of Thailand. Knowledge Management \& E-Learning, 10(4), 485-506. 


\title{
The opportunities and challenges of mobile and ubiquitous learning for future schools: A context of Thailand
}

\author{
Patcharin Panjaburee \\ Institute for Innovative Learning \\ Mahidol University, Thailand \\ E-mail: panjaburee_p@hotmail.com
}

\author{
Niwat Srisawasdi* \\ Division of Science, Mathematics, and Technology Education \\ Faculty of Education \\ Khon Kaen University, Thailand \\ E-mail: niwsri@kku.ac.th \\ *Corresponding author
}

\begin{abstract}
Today's new digital technologies and the spread of the internet have created numerous new opportunities and challenges for the education of the future. The rapid development of mobile and ubiquitous computing technology offered more chances to design and develop innovative learning approach with mobile devices in preparing schools and students for a future. In this paper we present case examples and the research results and reflections based on our recent developments and experiences in Thailand regarding how novel pedagogical applications, mobile technologies and software tools can be combined to enhanced students' learning at all level of education. To the end, we propose a possible direction for the transformation of traditional teaching in science to a novel of mobile and ubiquitous learning in an on-going large-scale educational project in Thailand. This is a challenge of our educational improvement to introduce the novel mobile-assisted learning approach, with the support of mobile devices, into classroom settings, innovative instructional practices and sustainability as the way of future schools in context of Thailand.
\end{abstract}

Keywords: Mobile technology; Seamless learning; Mobile learning; Ubiquitous learning; Learning strategy

Biographical notes: Dr. Patcharin Panjaburee is currently an Assistant Professor at the Institute for Innovative Learning, and a member of Frontiers of Educational Science and Technology (FEST) Research Network, Thailand. In 2010, Dr. Patcharin received her Ph.D. degree in Science and Technology Education from Mahidol University in Thailand. Her research interests include design and development of digital learning such as mobile and ubiquitous learning, digital game-based learning in computer science and mathematics, and design and development of personalized e-learning system in subject areas. Dr. Patcharin has published research articles in such professional journals as Computers \& Education, Interactive Learning Environments, Educational Technology \& Society, British Journal of Educational Technology, Innovations in Education and Teaching International, International Journal of Mobile Learning and Organisations, and Journal of Computers in Education. She served as an editorial board member for International Journal of Mobile Learning and Organisations (IJMLO). 
Dr. Niwat Srisawasdi is currently an assistant professor at Division of Science, Mathematics, and Technology Education, Faculty of Education, Khon Kaen University, Thailand, and a member of Frontiers of Educational Science and Technology (FEST) Research Network, Thailand. He is also a deputy director of Institute of Learning and Teaching Innovation at Khon Kaen University. In 2010, Dr. Niwat received his Ph.D. degree in Science and Technology Education from Mahidol University in Thailand. His research interests focus on technology-enhanced learning in science, digital and active learning, nanoscience and nanotechnology education, and technological pedagogical and content knowledge in STEM fields. Dr. Niwat has published research articles as book chapter with Springer, American Chemical Society, and IGI Global publishers, and in professional journals as Interactive Learning Environments, Educational Technology \& Society, International Journal of Mobile Learning and Organisation, Asia-Pacific Forum on Science Teaching and Learning, and Journal of Computers in Education. He served as an editorial board member for International Journal of Mobile Learning and Organisation (IJMLO).

\section{Introduction}

The rapid development of ubiquitous computing technology, which enables people to seamlessly utilize huge amounts and various kinds of functional objects anytime and anywhere through network connections, has enabled many possibilities of emerging pedagogical applications in order to improve quality of education. In recent years, the integration of technologies underlying ubiquitous computing and wireless communication with the supports of mobile devices have created innovative learning environment in schools (Hung, Lin, \& Hwang, 2010; Hwang \& Chang, 2011), and this technologyenhanced learning development allows learners to experience new learning situations beyond the classroom. This new development of school learning environments could offer learners a new way to infuse learning into daily life with adaptive supports, and engage and motivate learners with anytime and anywhere learning. Regarding to the development, Hwang, Tsai, and Yang (2008) pointed out that the progress of wireless communication and sensor technologies have evolved the research and development of elearning to mobile learning (m-learning), and now is evolving from $\mathrm{m}$-learning to ubiquitous learning (u-learning). In addition, ubiquitous learning is characterized by providing intuitive ways for identifying right learning collaborators, right learning contents and right learning services in the right place at the right time (Yang, 2006), and ubiquitous learning environment could be distinguished into three kinds of learning service, i.e. seamless service, context-aware service, and adaptive service with regarding to its features and potentials for learning (Hwang, Tsai, \& Yang, 2008). As such, it is crucial for researchers and practitioners to find effective ways to design, develop, and implement ubiquitous learning environments and technologies in a wide variety of learning settings for todays' learners.

With the development of ubiquitous learning technologies during the last two decades, the views of educational reforms have been transformed and the research and developments of mobile and ubiquitous learning has reached an unprecedented height in developing countries such as Thailand. In a context of Thailand, mobile and ubiquitous learning have been transformed the whole philosophical perspective of teaching and learning in schools and provided us with the opportunity for close interaction between teachers, learners, and contents with improved standard of digital learning materials compared to what was existing only with the printed media. In the past decade, a number 
of studies have been conducted to investigate the impacts of mobile and ubiquitous learning models on students' learning performances at all level. To provide an educational position of opportunities and challenges of mobile and ubiquitous learning in Thailand, this paper first introduces the context of mobile technology use trend in Thailand education and literature on mobile and ubiquitous learning in education and its opportunities for renovating traditional learning approaches. Then, the rationale and instructional design and development of technology-enhanced ubiquitous learning approach and environment in context of Thailand would be presented to demonstrate how the ubiquitous learning modules are constructed for promoting favorable school learning environment to digital native students in different levels of education within three exemplars. Finally, we discussed the benefits and drawbacks of the developed ubiquitous learning approach and suggested some future design and development issues. Moreover, an ongoing educational project focused on mobile and ubiquitous learning in middle school science would be described to provide the challenge position of Thailand on mobile and ubiquitous learning in schools.

\section{Context and literature}

\subsection{Trends of mobile use for education in Thailand}

In Thailand, a series of national ICT policy frameworks has been established as a central component of Thailand's economic development strategies for several decades. The goal of these strategies has been to use ICT to create a society that is smart and information literate, where knowledge benefits citizens and society as a whole, called "Smart Thailand" (Ministry of ICT, 2009), and Education has been a key pillar in these efforts. Information Technology (IT) implementation in various sectors has formally been initiated since 1992, while the first national IT policy has been formally proposed in 2000, with the goal to utilize IT to achieve economic prosperity and social equity (Laohajaratsang, 2010). The development of IT literate workforce has been set as a main objective in this national plan, and the "SchoolNet Thailand" was a prioritized project that aim to empower all schools to access internet-based information resources. In the next ten years, the second phase of national ICT policy has set the key objective to exploit the benefits of Information and Communication Technology (ICT) to drive Thailand in order to be knowledge-based society and economy (Makaramani, 2013). For Thailand, the recent growth in the adoption and use of mobile devices, e.g. smartphone and tablet PC, is relatively increased every year. In 2018, Thailand had 55.56 million unique mobile users in use with a penetration of 80 percentages regarding the overall population in this country (Funk, 2018). Moreover, Kemp (2018) mentioned that the digital growth is quite significant in all areas except the mobile users as this rate already has been incredibly high, with 98 percentages of the adult population that currently use any type of mobile phones, all over the country. According to the statistics, it clearly makes Thailand is a mobile first country. In term of education, the high level of mobile penetration is expected to spark demand for mobile learning service driving the demand for new infrastructure and the mobile internet system in future schools.

As mobile devices, such as smartphones and tablet PC, become more accessible and affordable, Thailand has announced ambitious plans to roll out tablet computers for schools. Clearly, it is important to examine how their features and functionalities might be tailored for educational purposes. With the support of mobile devices in education, ubiquitous learning represents something fundamentally different from earlier efforts to 
infuse information and communication technology into education. Thailand has made significant investments in information and communication technology (ICT) education over the past few decades, setting out plans to use ICT as a tool to enhance teaching and learning for promoting the acquisition of digital competencies needed for success in the $21^{\text {st }}$ century (Ministry of Education, 2015). Despite Thailand's current status as a developing country, the government's policy is radically in favour of adopting mobile device culture in schools. As schools begin to accept the growing mobile culture, potential issues are being identified in the widespread adoption of mobile technology in the classroom. The first educational reform effort focused on the use of mobile technology in education began in 2011, when Thai government proposed an initiative development programme called One Tablet Per Child (OTPC) for creating equality in educational opportunities and improving quality of education for both urban and rural children in compulsory or basic education level. The OTPC programme intended to provide students at all levels with mobile device i.e. tablet PC for educational purposes and set up a student-centred mobile learning approach and national e-learning system to encourage lifelong learning for all (Ministry of Education, 2011; OECD/UNESCO, 2016). A large number of OTPC android tablet PC, loaded with a number of learning objects, i.e. e-books, videos and interactive content, in five subject areas including mathematics, science, Thai language, social studies and English language, have been administered to students for schools nationwide (Ministry of Education, 2011). Fig. 1 illustrates an example of OTPC android tablet and its installed contents contributed to elementary school in Thailand.
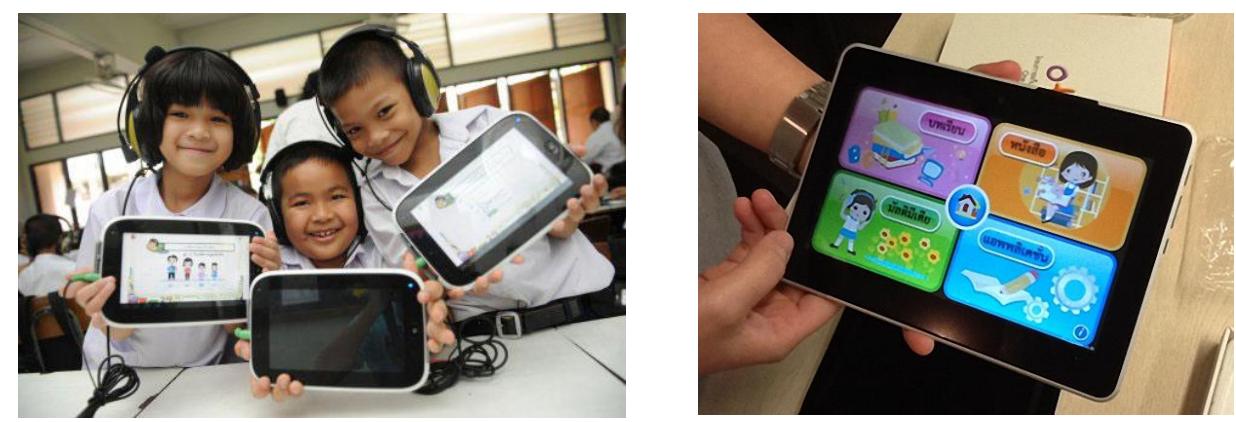

Fig. 1. An illustration of OTPC tablet with Thai elementary school students (Left) and installed subject contents and free applications on OTPC tablet (Right)

According to the implementation of mobile technology in Thai education, there are still considerable challenges in realising how to use the technology to improve teaching and learning in schools. In the last five years, this project has been attracted by researchers, educators, developers, and administrators around the country, and this is an opportunity to renovate technological and pedagogical application platform for improving educational quality of our nation and new challenges are derived from mobile and ubiquitous learning experience of Thailand.

\subsection{Concept and related works on mobile and ubiquitous learning}

With the increasing popularity of digital technology development and wireless internet technology, researchers, educators, and developers are offered more chances to design, develop, and implement more challenge and complicated teaching tasks for promoting knowledge and skills over and above subject content knowledge (Boyce et al., 2014). From the perspective of schools during the last decade, the ubiquitous nature of mobile 
technology has been recognized by many researchers and educators (Looi et al., 2014). The "anywhere and anytime learning" with the technological affordances of mobile technology has a very broad-sense definition. For more clarify, Hwang, Tsai, and Yang (2008) characterized the similarities and differences among ubiquitous learning, mobile learning and context-aware ubiquitous learning as display in Fig. 2.

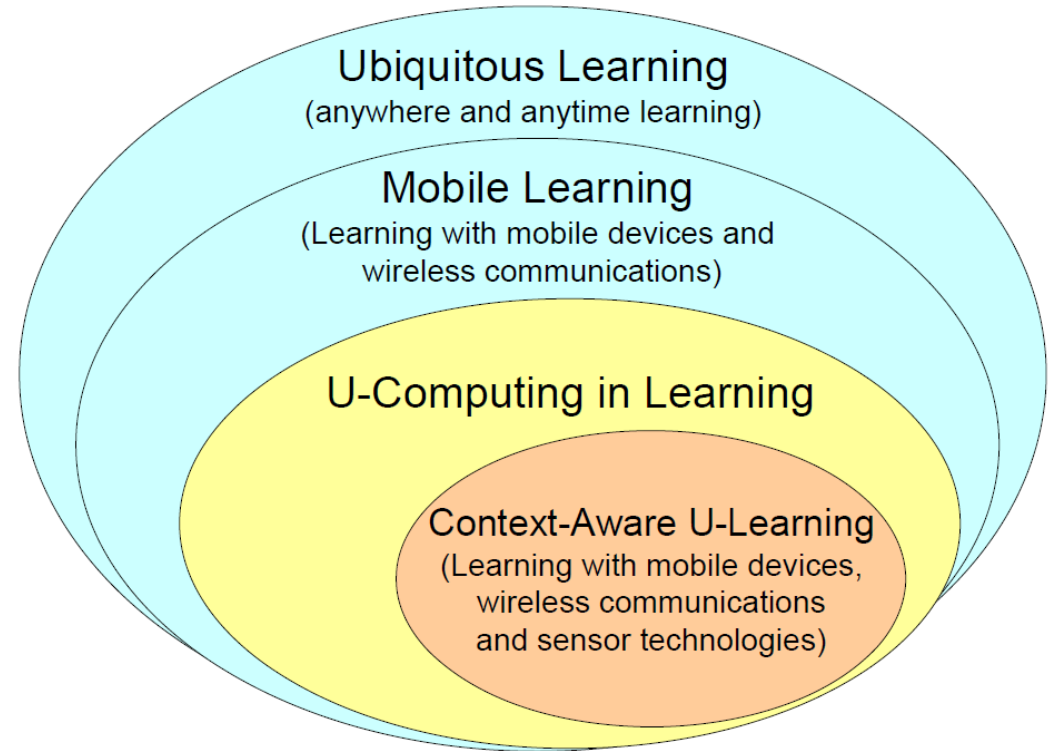

Fig. 2. The relationships among ubiquitous learning, mobile learning, and context-aware ubiquitous learning. Adapted from Hwang, Tsai, and Yang (2008)

According to Hwang, Tsai, and Yang (2008)'s conceptual idea, ubiquitous learning usually defined as any learning environment that allows students to access learning content in any location at any time, no matter whether wireless communications or mobile devices are employed or not, and mobile learning is defined as the learning environment which allows students to access learning content via mobile devices with wireless communications. In addition, mobile learning makes sense only when the technology in use is fully mobile with the support of internet network and when the users of the technology are also mobile while they learn (El-Hussein \& Cronje, 2010; McQuiggan et al., 2015). While context, i.e. current time, the location of the user, behaviour of the learner, temperature and humidity of the learning environment, is an important aspect of mobile learning, an important affordance of the learning environment is context awareness. As such, a special definition of ubiquitous learning that employs mobile devices, wireless communications and sensor technologies in learning activities has been emerging and it is called context-aware ubiquitous learning (Hwang, Tsai, \& Yang, 2008).

Since the anywhere and anytime learning has become one of the learning model trends, many scholars have conducted related research on how to use special functions of mobile devices for educational purposes in many possibilities. In the past decade, various studies concerning mobile and ubiquitous learning have been conducted in both inside and outside the school class, such as museums, classrooms or labs (Hall \& Bannon, 2006). For example, Chu, Hwang, and Tsai (2010) and Hwang, Shi, and Chu (2011) developed a grid-based mind tool displayed on mobile device and employed as context-aware 
ubiquitous learning based on a knowledge engineering approach to guide elementary school students to observe the features of plants in a natural science course. The results showed that the context-aware ubiquitous learning approach not only promotes learning motivation, but it also improves the learning achievements of individual students. In context of mobile learning as abovementioned, Wu, Hwang, Tsai, Shen, and Huang (2011) developed a repertory grid-oriented clinical mobile learning system for a nursing training program, and the results show that the innovative approach is helpful to students in improving their learning achievements and attitude and reducing cognitive load during their learning. In addition, Tsai, Shen, Tsai, and Chen (2016) implemented a flexible means of ubiquitous learning with a mobile application of web-mediated computational thinking to help first-year university students for developing practical computing skills, and the result showed that students who received the treatment of ubiquitous learning could have significantly better computing skills than those without.

Mobile, ubiquitous, and context-aware ubiquitous learning seems to be a pedagogic way to promote effective process of teaching and learning and enhance students' learning performance, both formal and informal contexts. Srisawasdi, Pondee, and Bunterm (2018) mentioned that the learning with mobile technologies offers a plethora of features and benefits that enable it to break the educational system wide open, engaging students in new ways and the mobility of learning makes educational experiences more meaningful. However, a challenge for the learning with mobile technologies in specific subject related to the pedagogical adoption of mobile technologies in school with regarding the affordances of mobile technologies (KukulskaHulme \& Shield, 2008). Therefore, the next section would be used to present pedagogical opportunities to transform traditional class with the support of the learning with mobile technologies in various techniques proposed upon previous studies' evidences.

\section{The opportunities for pedagogical transformation with mobile technology}

During the past decade, every area of education and training has been affected by the advancement of mobile technology. Currently, mobile devices are everywhere, and mobile learning has emerged as a potential educational environment to transform the world of learning and also to obtain improvements in the learning field. Regarding the possibilities offered by mobile technology, this poses new opportunities and new challenges to the educational systems for transforming school learning experience. With the importance of studying pedagogical research and development and transforming existing instructional methods for this new opportunity, many instructional models were grounded on the theoretical aspects of mobile and ubiquitous learning for the last decade. However, it is relatively new to Thailand educational system on how to transform traditional learning mode with the support of mobile technology, and design, develop, and implement mobile and ubiquitous learning approach for promoting students' learning performance over and above subject content knowledge. Moreover, there is a chance to design and consider which pedagogical approach would result in the more successful promotion of mobile and ubiquitous learning in any subject areas among students. In order to promote the learning with mobile technologies, Hwang, Chu, and Lai (2017) pointed out that technologies should not just be used as a channel for providing learning materials; instead, teachers should design learning activities regarding the features of the technologies and the needs of the subjects to ensure that the use of the technologies has greatest effects on students' learning performances. In order to promote the transformation of pedagogical applications for mobile and ubiquitous learning, Lai and 
Hwang (2015) reviewed effective teaching strategies with the support of mobile technology from the previous studies and then proposed a series of mobile and ubiquitous learning approaches for bridging the in-class and outdoor instruction in school. These ten strategies are: guided learning, peer assessment, video sharing, synchronous sharing, issue-based discussion, computers as mindtools, project-based learning, digital storytelling, inquiry-based learning, and contextual mobile learning, as display in Fig. 3.

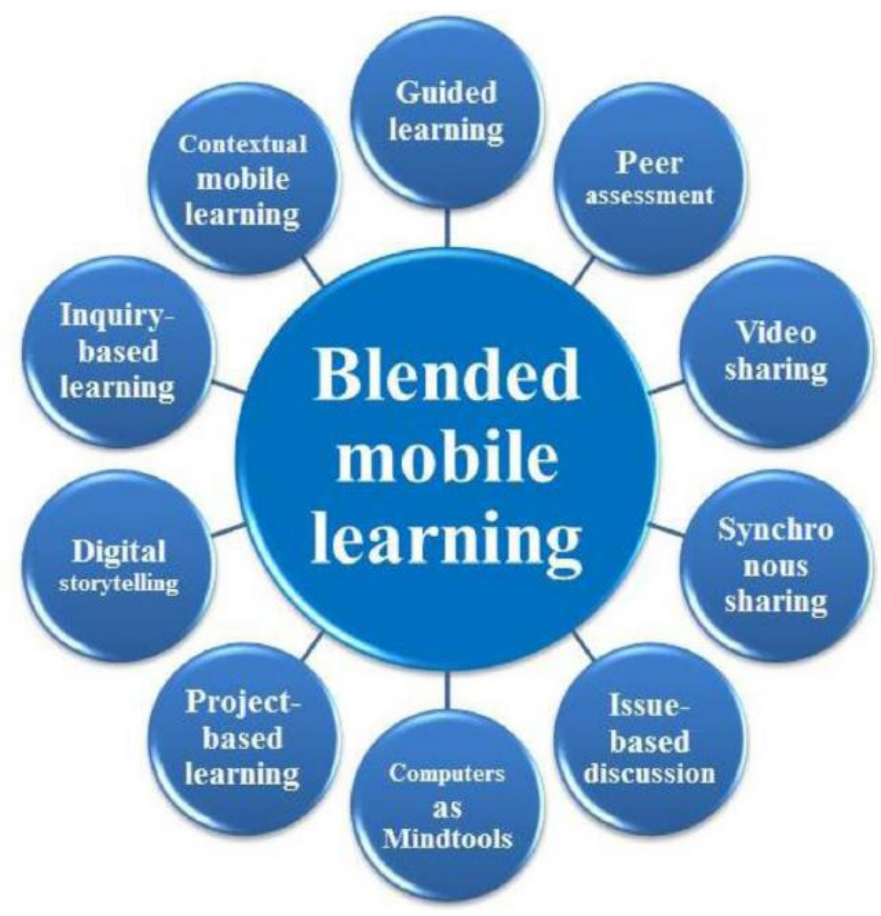

Fig. 3. Ten teaching strategies of blended mobile and ubiquitous learning mode. Adapted from Lai and Hwang (2015)

According to Lai and Hwang (2015)'s idea, the blended mobile learning model is used to bridge the traditional, in-class, and outdoor instruction through a set of effective and possible teaching strategies related to mobile and ubiquitous learning, where the two mobile learning modes help learners to connect the content of their textbooks or what they have learned in the traditional instruction to the digital resources and real-world learning targets. As such, there are pedagogical possibilities to transform traditional or conventional instruction into innovative and creative learning environment with the technological affordances of mobile technology with regarding particular context of school classes or courses. In particular, research and development on the possible uses and potentialities of mobile technologies is continuously growing in developed countries and some of developing countries, but in Thailand, research and development on mobile and ubiquitous learning is still limited. The lack of these comprehensive research and development could, however, bring some challenges to overcome the limited practice of mobile and ubiquitous learning in Thailand, a developing country, but at the same time it can bring some opportunities too. Therefore, researchers, developers, and practitioners have pedagogical opportunities to select and implement those abovementioned teaching strategies to find the effective way on the use of mobile and ubiquitous learning mode that are valuable and instructive in different settings and contexts. 


\section{Challenges in pedagogical and technological applications of mobile and ubiquitous learning in Thailand}

In order to transform learning practices with new technologies across contexts, designing effective technological support along with appropriate pedagogy is more complex than imagined, and there is no exact and easy solution to the development of learning supporting systems and technological tools to mediate process and practices in mobile and ubiquitous learning environments (Milrad et al., 2013). In contrast to developed countries, the improvement of quality of education with new technologies and pedagogies faces many challenges, most of which are not directly concerned with educational issues, but which have a direct effect on the quality of the teaching and learning processes (Valderrama Bahamóndez \& Schmidt, 2011). The potential of mobile phones for education in developing countries has already been recognized (Kam et al., 2009). Particularly, a challenge in pedagogical and technological applications of new shape of learning with mobile technology in developing country, i.e. Thailand, is that how to shift the epistemological beliefs of individual teachers and learners from the transmission and receiving of knowledge, skills, and attitudes to the facilitation and self- and coconstruction of those kinds of outcomes. Moreover, the very significance challenge of mobile and ubiquitous learning in a developing country is pedagogical ability to make learning mobile, away from the school or classroom environment as anywhere and anytime learning. In addition, another challenge for mobile and ubiquitous learning is the level of social acceptance on the use of mobile devices by policy makers, school principals, educational supervisors, and parents, and also trouble accessing the internet, or experience difficulty in affording technology that enables learning in mobile and ubiquitous learning environment. However, the crucial challenge for educators, researchers, and developers in developing countries is to find effective ways to design and develop, implement, and evaluate innovative mobile and ubiquitous learning technologies and approaches in a wide variety of learning settings, e.g. various groups of students and instructors in high schools and at universities, and different disciplines in the learning materials. Our earlier research has explored the possibilities of mobile and ubiquitous learning in multiple context of education, where the design and impacts of specific pedagogical and technological application have been investigated. All of the works here presented have conducted studies in Thailand. In the following sections we present the most outstanding research found in literature, about the use of mobile and ubiquitous learning in unprivileged and/or developing regions settings.

\subsection{An example of ubiquitous learning in higher education}

The teaching and learning of computer programming is one area of computer education curriculum. The students can subsequently apply the programming knowledge to other works in their surroundings. Thus, redesigning learning experiences to go beyond the classroom walls and the confines of the university day in order to encourage university students' achievement in programming is warranted. It is a challenge to seeking how the computers and communication technologies can serve as a tool for facilitating learning programming inside and outside classroom (Serrano-Cámara et al., 2014). Moreover, it remains a challenge to engage students' sharing explanations with peers and to trigger students' constructing knowledge in large classroom; thus, it is crucial to afford students learning activities for constructing tenable concepts (Lawson, 2000). Accordingly, the development of computers and communication technologies integrated inquiry-based learning has become an important and challenging topic (Raes, Schellens, de Wever, \& Vanderhoven, 2012). 
In recent years, the rapid advancement of mobile devices and wireless communication technologies has built a ubiquitous learning environment, where students can use computers in a public environment and use a mobile device accessing the network with wireless communication technologies, at any time (Uemukai, Hara, \& Nishio, 2004). In this case study, an enhanced inquiry-based learning approach was proposed to develop a ubiquitous learning support system for engaging university students in meaningful learning activities and supporting them in constructing tenable knowledge of computer programming. During participating in the ubiquitous learning support system, a student was asked to coding computer program in the specified code editor area to investigate the question/task as shown in Fig. 4. He/she could see additional information related to the question/task during coding.

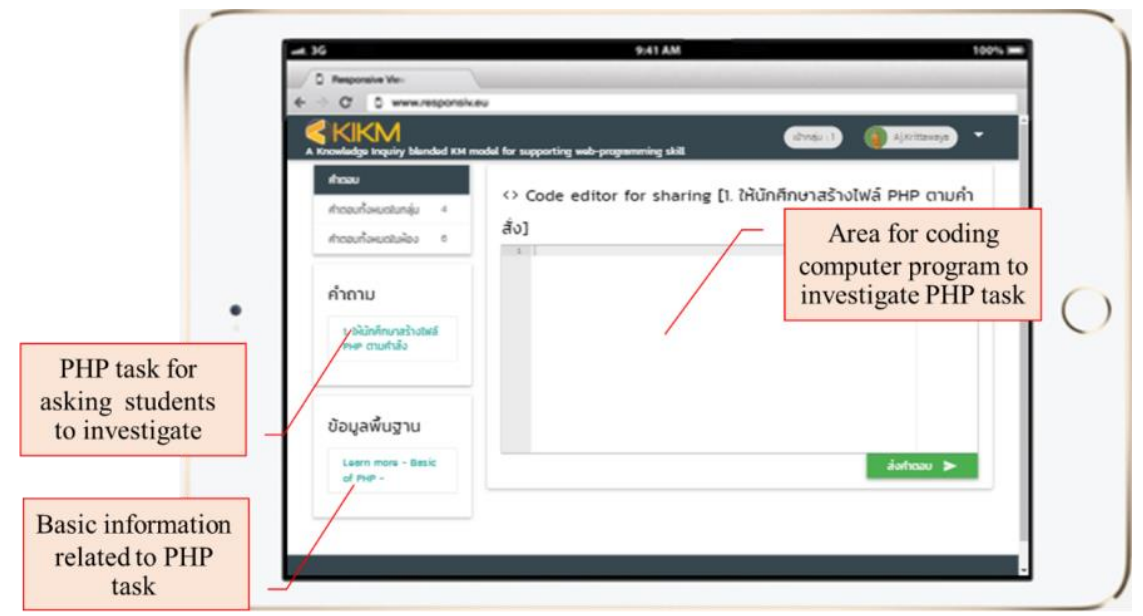

Fig. 4. An illustration of a ubiquitous learning system for asking each student to code PHP program regarding to PHP problem/task

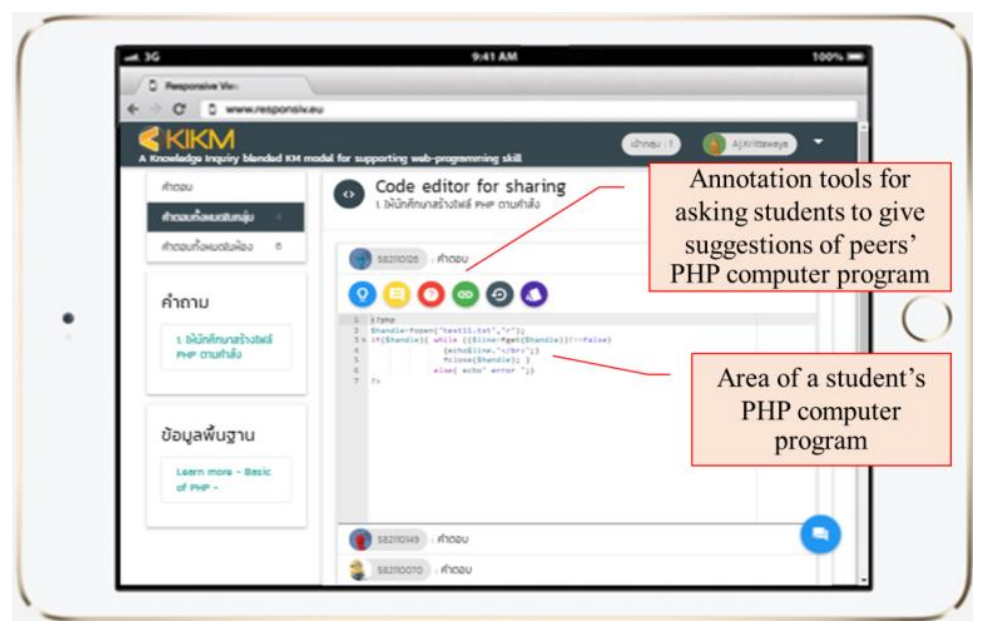

Fig. 5. An illustration of a ubiquitous learning system for asking each student to give suggestions to peers by using annotation tool

When finishing coding, the student was asked to submit his/her answer into the system for further discussion with peers. The student was asked to use annotation tool to 
inquire or give the recommendation into the answer/computer programming to peers as shown in Fig. 5. Moreover, the students can use the chat room in order to communicate and discuss about the strengths, weaknesses, and limitations of their own and peers' programming. In this stage, the teachers joined the system to give a hint or guideline to students. After finishing discussion, the system navigated the student to revise his/her computer programming once again. That is, this stage allows each student to construct his/her knowledge about computer programming, for example, understanding the principle of writing PHP Function, using PHP built-in function and creating PHP userdefined function in specific command.

To evaluate the effectiveness of the proposed ubiquitous learning system, an experimental study was conducted with second-year-university students, in a public university located in northern region of Thailand, on a topic of PHP function in a webprogramming course by comparing with traditional instruction: the teachers played the main role in encouraging students to conduct peer explanations and construct their own PHP function knowledge. Fig. 6 illustrates students' learning interaction with the proposed ubiquitous learning system in a manner of anywhere and anytime learning.
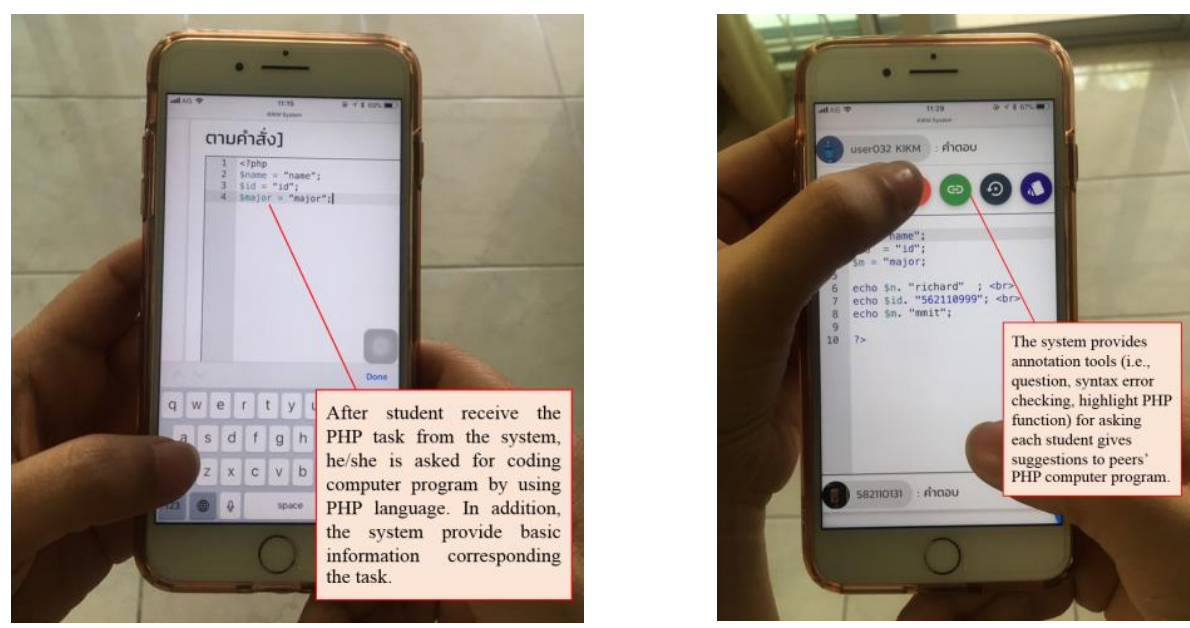

Fig. 6. Illustrative examples of anywhere and anytime learning interaction with the proposed ubiquitous learning system

From the experimental results, it was found that the proposed ubiquitous learning system was useful to improve the students' content understanding with the provided inquiry-based learning and knowledge management activities; moreover, it was useful to improve the students' learning performance (Thongkoo, Panjaburee, \& Daungcharone, 2017). Results that compared outcomes with those of a control class, showed that the students, who participated in the proposed ubiquitous learning system had better learning achievement than those who learn in traditional instruction. In addition, it was found that female students, who learned with the developed system, improved learning achievements on the topic better than those who learned with the traditional teaching approach, and male students, who learned with the developed system, improved learning achievements on the topic better than those who learned with the traditional teaching approach. As the abovementioned results, Thongkoo, Panjaburee, and Daungcharone (2017) found that the proposed ubiquitous learning system was more effective than the traditional learning environment in improving university students' programming learning achievement, and the proposed ubiquitous learning system benefited both female and 
male students' learning achievement and perceptions to the same extent implying that the proposed ubiquitous learning system could reduce the gap between gender differences.

\subsection{Examples of mobile learning in compulsory education (primary and secondary school)}

\subsubsection{An example of mobile-assisted science learning in secondary school}

To enhance science learning in secondary schools, scientific laboratory was recognized as a promising instructional strategy for promoting middle and high school students' understanding in science concepts, science process skills, and attitude towards science. For instance, Tobin (1990) suggested that meaningful learning is possible in the laboratory if the students are given opportunities to manipulate equipment and materials in an environment suitable for them to construct their knowledge of phenomena and related scientific concepts. For the past several decades, inquiry-based learning is becoming a common teaching paradigm all over the world for science education at both primary and secondary school, and teaching science by inquiry-based laboratory was considered as a central part of pedagogy for teaching in school science programs (Hofstein \& Lunetta, 2003; Hofstein \& Mamlok-Naaman, 2007; Srisawasdi, 2015). Inquiry also refers to the activities of students in which they develop knowledge and understanding of scientific ideas, as well as an understanding of how scientists study the natural world (National Research Council, 1996). In term of school physics, inquirybased learning should provide students to gain a deeper understanding of fundamental physics concepts and, at the same time, strengthen scientific skills through developing and using models, planning and conducting investigations, analyzing and interpreting data, using mathematical and computational thinking, and constructing explanations (National Research Council, 2000). However, researchers largely mentioned that students find the subject of physics to be obscure and difficult to learn because of its complex and abstract relations, and this causes students to hold misconceptions (Srisawasdi \& Panjaburee, 2015). To enhance the learning of conceptual physics in secondary school science, there are a number of inquiry-based laboratory learning in physics, such as the Workshop Physics (Laws, Willis, \& Sokoloff, 2015), Real-Time Physics (Sokoloff, Laws, \& Thornton, 2007), Interactive Lecture Demonstrations (Thornton \& Sokoloff, 1998), and Conceptual Labs (Bernhard, 2010), and their effectiveness has been reported for many past decades in the community of science education.

Currently, inquiry-based laboratory learning with digital technology is generally seen as a promising area in science education, and technology-enhanced inquiry laboratory learning has increasingly become a pedagogical approach for enhancing students' conceptual learning and development in school science (Srisawasdi \& Kroothkeaw 2014; Srisawasdi \& Sornkhatha 2014). The technology-enhanced inquiry laboratory learning may involve web-based learning environments (e.g., online adaptive learning environments, online interactive learning environments, intelligent tutoring system, learning management system, and so forth), handheld- or microcomputer-based laboratory, computer simulations or animations, computer or digital games, augmented reality (AR), virtual reality (VR), and mobile or smartphone applications as inquiry tools to facilitate students learning in science laboratory (Srisawasdi \& Panjaburee, 2016). With the rapid growth of mobile technology, the use of mobile devices has influenced traditional practices in inquiry-based laboratory learning and it has become a new research area because mobile technology offers new opportunities for student learning, engagement and motivation into science laboratory. With the support of mobile devices, 
the flipped classroom model of teaching can, moreover, be an ideal venue for turning a traditional science laboratory into an engaging or active inquiry-based learning environment (Love et al., 2015). Both flipped learning, which usually involves students watching videos before class, and inquiry-based learning, which focuses on allowing and encouraging students to develop material on their own, emphasize active learning and critical thinking through activities such as group work and presentations while minimizing lectures, and the two teaching styles can complement each other and be implemented concurrently (Capaldi, 2015). Regarding the potential benefits of using mobile technology for inquiry-based laboratory learning and flipped learning, a mobileassisted flipped-inquiry learning approach is proposed for promoting anytime anywhere inquiry-based learning with mobile device and wireless communication and enabling a personalize science learning experience in this case study.

To promote high school students' physics learning performance in liquid pressure phenomena, the mobile-assisted flipped-inquiry learning approach has been created and implemented with twelve-grade students in a public secondary school located in northeastern region of Thailand. A series of video-based lesson has been created as preclass session to engage students into the in-class session of meaningful and authentic learning in physics of liquid pressure phenomena, as showed in the left of Fig. 6. To facilitate students' inquiry-based laboratory learning with the support of mobile device and wireless communication, an interactive PhET simulation, named Under Pressure, created by University of Colorado, Boulder, has been employed and delivered the simulated experiment via their own smartphone and tablet PC provided by teachers, as illustrated in the right of Fig. 7.
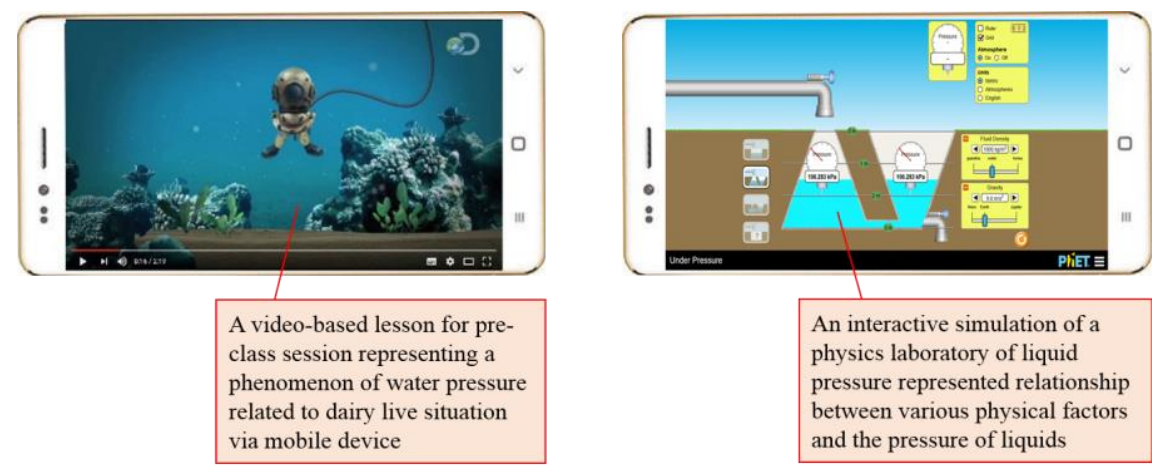

Fig. 7. Illustrative examples of a video clip representing the phenomenon of liquid pressure (left) and an interactive PhET simulation (right) displayed on mobile device

A three-stage learning process in a matrix of computer-based open inquiry laboratory (Srisawasdi, 2012; Srisawasdi \& Sornkhatha, 2014; Srisawasdi \& Panjaburee, 2015) has been adapted to generate the interconnection between pre-class and in-class learning process for the mobile-assisted flipped-inquiry learning approach. In the first stage of this generated approach, teacher used video-based lesson to stimulate curiosity and interest through an authentic scientific scenario with an open-ended inquiry question, and then provide essential theory and basic or background knowledge to foster testable hypotheses generation, as the pre-class session. For the in-class session, the second stage begins with the practical assignment for students to design their own experiment and perform the experiment with the simulation via their own smartphone or tablet PC, and then analyze obtained data to verify the generated hypotheses. In the third stage, the students were asked to articulate and communicate their investigation findings and then 
drawn conclusions to address the teacher-provided inquiry question. Fig. 8 illustrates the inquiry-based learning process with interactive simulation occurred in the in-class session.
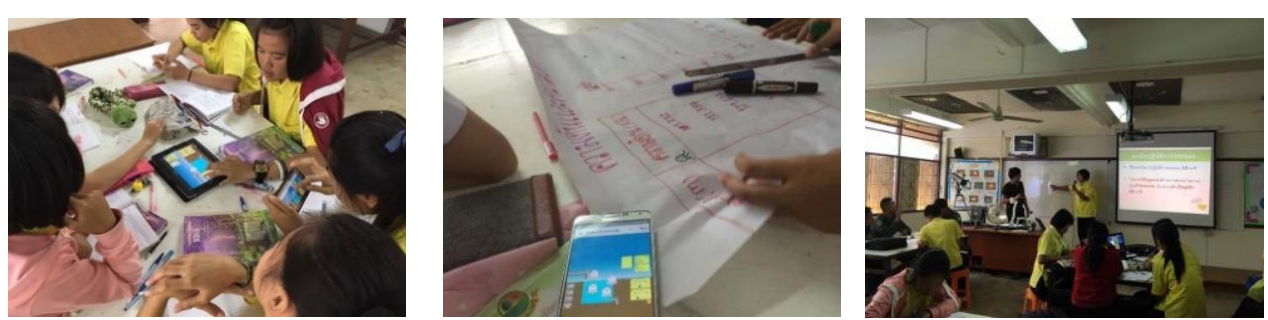

Fig. 8. Examples of the in-class session with mobile-based inquiry laboratory learning: students collaboratively worked to interact with interactive simulated laboratory in a small group by using both their own smartphone and tablet PC provided by teacher (left); individual group analyzed the experimental data and prepared their presentation (middle); individual group presented their own findings to the whole class (right)

The results showed that conceptual learning performance on liquid pressure at both observable and unobservable level of the phenomena was superior in the high school students who participated with mobile-assisted flipped-inquiry learning approach as compared to other learning settings (Chaipidech \& Srisawasdi, 2017),

\subsubsection{An example of mobile-assisted science learning in primary school}

Digital game-based learning (DGBL), which is one of student-centered instructional approaches, incorporates learning content or learning principle into the computer game for engaging students to achieve the educational goals. In recent years, many studies have developed and reported that DGBL was able to promote students' learning interest and motivations (Ebner \& Helzinger, 2007; Hung, Lin, \& Hwang, 2010). For example, Hwang and Chang (2011) revealed that after participating the digital game-based learning via mobile phone in the learning activity, the student improved in their learning interest and attitudes.

In light of DGBL approach, a digital game-based learning has been developed by incorporating the guided inquiry-based learning approach into gaming scenario for encouraging and enhancing students' learning performance in physical science concept of forces and motion in primary school level. In this study, a 2D role-playing digital game has been designed and developed to support an interactive inquiry learning with a series of physical science concepts regarding the characteristics of force and motion, the force composition, the direction of force, the same direction of forces calculation, and the calculation of resultant force. Moreover, the game requires less supplied power, which is well supported in mobile learning for the most elementary school in Thailand. With the benefits of the scientific inquiry approach and the digital game, a proposed guided inquiry-oriented digital game has been investigated its impact on primary school students' learning performance in science. The digital game embedded with the guided type of scientific inquiry approach consists of five components: (i) open-ended inquiry question; (ii) scientific background information; (iii) procedure/design; (iv) data and result analysis; and (v) result communication and conclusion (Komalawardhana \& Panjaburee, 2018). Fig. 9 illustrates the guided inquiry-oriented digital game on a mobile device.

To evaluate the effectiveness of the proposed guided inquiry-oriented digital game, a total of 79-fourth and fifth graders of a public primary school in the central part 
of Thailand were recruited for an experimental study. In this study, the students were assigned to individually participated with the developed game, and then shared the results in the game with their friends in the science class time, as illustrates in Fig. 10.

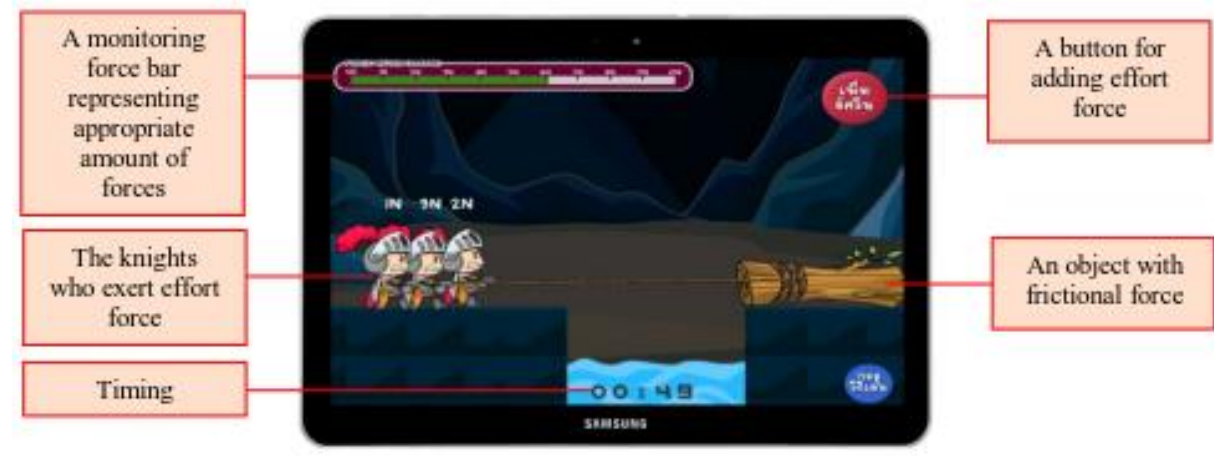

Fig. 9. An example of the guided inquiry-oriented digital game about forces and motion on tablet PC
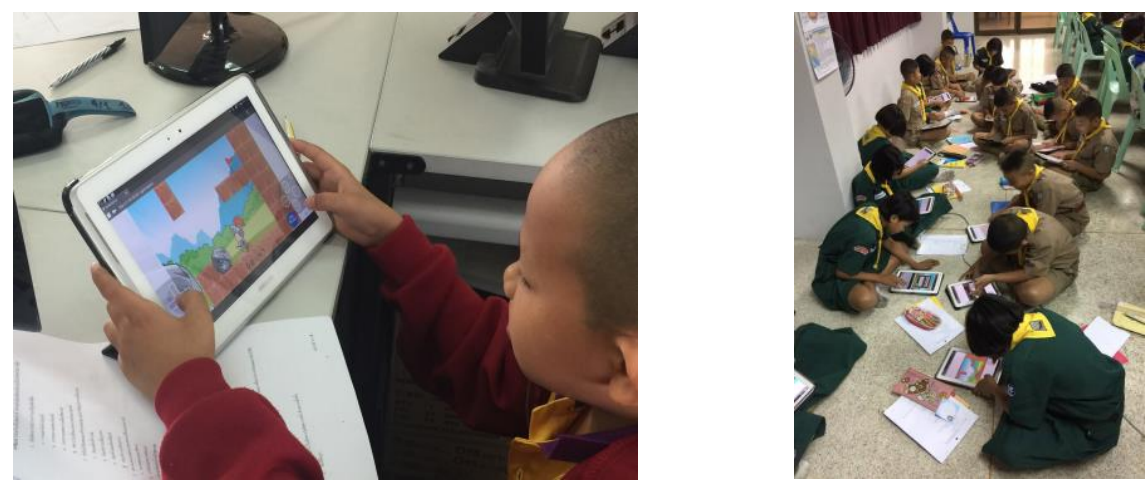

Fig. 10. Examples of science class session with the guided inquiry-oriented digital game about forces and motion on tablet PC

To evaluate the proposed digital game material, the primary school students were measured a degree of perceptions toward the game and their learning interest of science with the game by questionnaires at the end of the science lesson. The result showed that their perceptions toward the digital game were not influenced by the student's gender and learning style, and their genders and learning styles were not significant different with the average of the learning interest levels regarding the science learning with the digital game. In a conclusion, this study revealed that the development of digital game embedded with scientific inquiry approach is suitable digital game design for deceasing gap of learning style and gender differences among Thai primary school students (Komalawardhana \& Panjaburee, 2018).

\subsection{An example of context-aware ubiquitous learning in primary school education}

Recent progress in wireless and sensor technologies has led to a new development of learning environments, one of which is the context-aware ubiquitous learning environment that is able to sense the learner's situation (or a situation of the real-world 
environment), and provide learning supports based on radio-frequency identification (RFID), wireless networks, embedded handheld devices, and database technologies (Hwang, Tsai, \& Yang, 2008). Context-aware ubiquitous learning is being increasingly recognized as being an innovative and important approach in science learning (Srisawasdi et al., 2016). In the domain of current science education, context-aware ubiquitous learning plays a critical important role to provide opportunities to support science learning both inside of and outside of classroom in a manner of anyone, anywhere, and anytime learning with mobile devices, wireless communication, and sensor technologies (Kongpet, Srisawasdi \& Feungchan, 2015; Nasaro \& Srisawasdi, 2014; Rogers et al., 2005). In the past decades, researchers have been widely conducting research concerning mobile and context-aware ubiquitous learning and have reported the effectiveness of context-aware ubiquitous learning approach in various learning contexts, and the findings indicated that most students had demonstrated substantial improvements and extended in their inquiry abilities (Hung, Lin, \& Hwang, 2010; Hung et al., 2013; Meuansechai, Feungchan, \& Srisawasdi, 2015).

In context of Thailand, a context-aware ubiquitous learning in school science was developed and then implemented in a public primary school located in northeastern region of Thailand. In this study, context-aware ubiquitous learning system called the "Answer Me" has been created as an instructional tool to facilitate students' scientific investigation by observing and identifying learning objects in the real world, as an infield or outside the classroom by using tablet PC obtained from Ministry of Education, available wireless communication in the village, and the built-in camera of the tablet, as a sensing technology. Fig. 11 displays a tablet screen example of the Answer Me android application for primary school students.

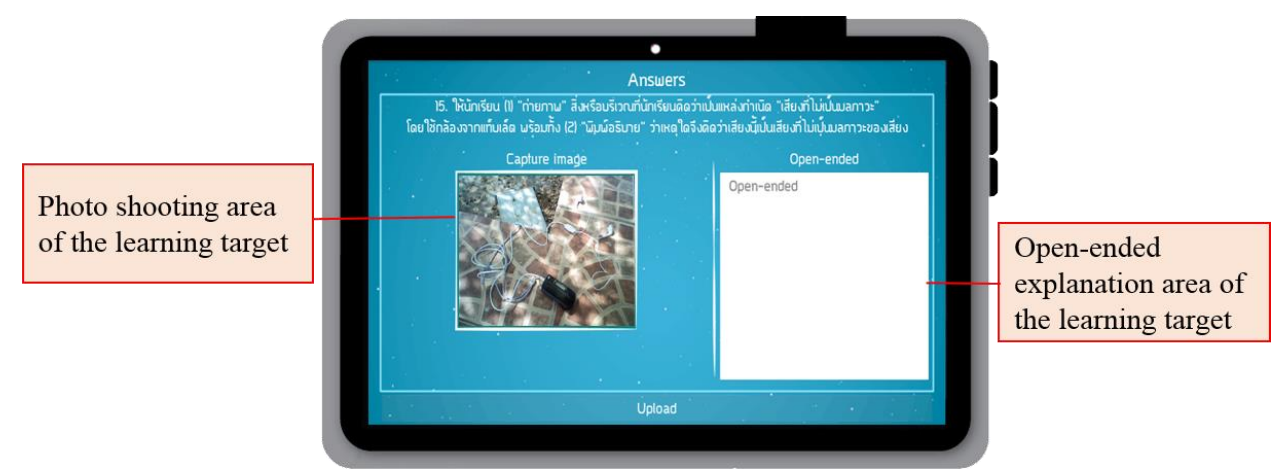

Fig. 11. An example of the "Answer Me" android application's student interface on tablet PC

Regarding the predict-observe-explain sequence of inquiry learning activity, teacher can monitor students' responses following the assigned learning task on the learning target. Fig. 12 presents the learning records of the participated students based on the predict-observe-explain inquiry process.

This case study recruited fifth- and sixth-grade students in an urban public primary school located in northeastern region of Thailand to participate the proposed context-aware ubiquitous learning activity regarding predict-observe-explain inquiry practice, with the support of a prompt-based ubiquitous learning system called Answer Me. In this study, the predict-observe-explain sequence was implemented in a series for probing and fostering students' conceptual understanding on sound wave and for increasing the students' motivations to learn science by participating in the learning 
process. In these learning activities, the students could receive instant prompts to guide them through a complete a series of predict-observe-explain learning tasks via observing the real-world targets and answering a series of questions related to the characteristics of the target. To complete the learning tasks, the students were divided into dyads, were assigned to take photos of the targets using digital cameras, and were further assigned to take notes in order to explain the photos highlighting the conceptual ideas in science. During the field trip activities, students could discuss ideas with other classmates and could collaboratively execute the prompting. If they failed to correctly identify and explain the present learning target, the teacher could provide learning supports at the right place and at the right time during the field trip in the village. Then, the teacher monitored the progress of the in-field observations until they were finished with the real-world targets. Then they received a prompt requesting them to return to the classroom. Fig. 13 displays examples of primary school students' learning action in outdoor activity with the use of context-aware ubiquitous learning approach.

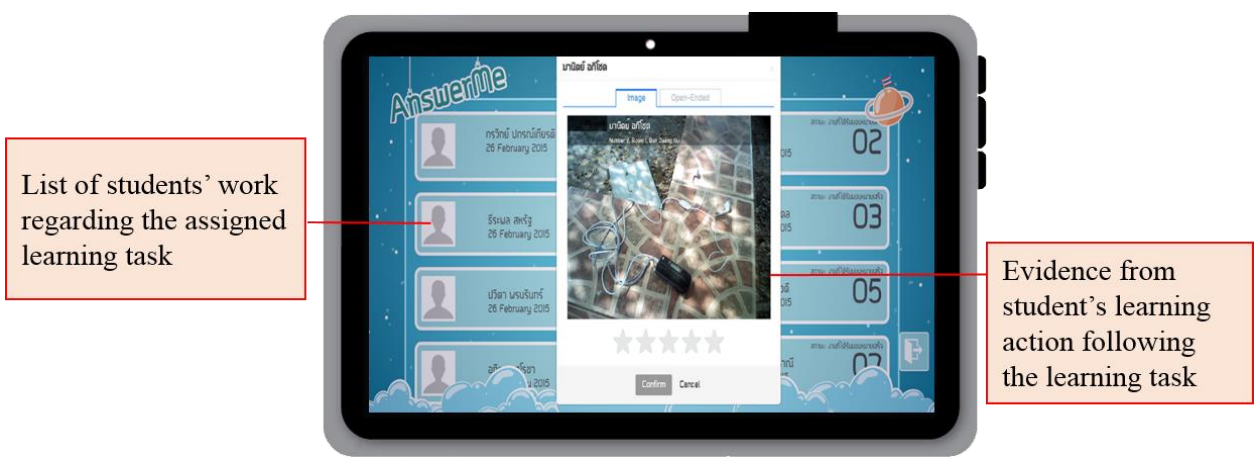

Fig. 12. An example of the recording database of students' work and responses on tablet $\mathrm{PC}$
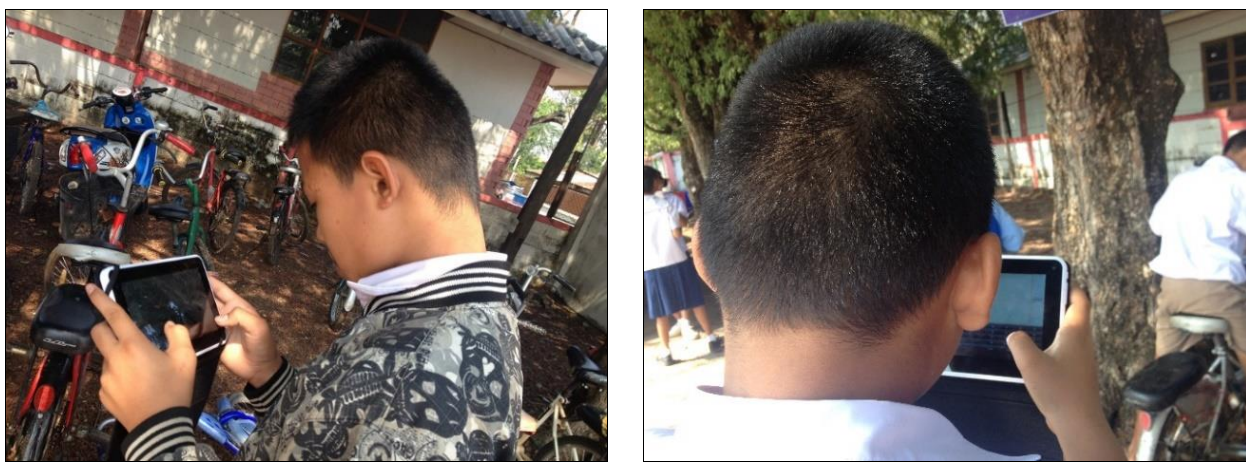

Fig. 13. An illustration of context-aware ubiquitous learning activities by using in-field observation with the support of tablet PC

Results that compared outcomes with those of a control class, showed a positive effect on the improvement of conceptual learning outcomes on sound wave phenomena and also promoting better science motivation (Meuansechai, Feungchan, \& Srisawasdi, 2015; Srisawasdi et al., 2016). 


\section{A proposal to transforming traditional middle school science by mobile and ubiquitous learning in Thailand}

The vision of transforming traditional learning practices with mobile and ubiquitous technologies has not yet been fully crystalized, especially with regard to enabling anywhere and anytime learning and collaboration across contexts. Especially, researchers have pointed out that mobile technologies should not only be used as a delivery channel for providing content and learning materials, but instructors should also design meaningful learning activities based on the functions and features of the mobile technologies to meet the needs of the subjects and the requirement of students' learning performances (Hwang, Chu, \& Lai, 2017). Moreover, the designing of learning process and pedagogical practice with the aid of digitalized content and mobile and ubiquitous technology system and environment is a complicated process (Srisawasdi \& Panjaburee, 2016). To enhance technology-based learning in any particular domains and subject areas, researchers, educators, teachers, and developers need to know how the learning with particular technologies can enhance the representations of specific content knowledge by making the content easier to learn and strategically promote particular learning processes or pedagogical practices (Koehler, Mishra, \& Cain, 2013; Mishra \& Koehler, 2006). To make mobile and ubiquitous learning effectively, the use of innovative or emerging pedagogies such as inquiry-based learning, knowledge engineering approach, seamless learning, collaborative learning, and self-regulated learning should be an important research and development issues.

To improve the quality of education, governments and researchers in many countries are making a great deal of effort to bring mobile and ubiquitous learning into both compulsory and higher education. Examples comprise inquiry-based seamless learning project in Taiwan (Hwang \& Tsai, 2011), personal inquiry (PI) project in the United Kingdom (Anastopoulou et al., 2012), geometry mobile (GEM) project in Sweden (Sollervall et al., 2011), Sustainable Seamless Learning (SEAMLESS) project (Looi et al., 2010) and My Chinese Language ubiquitOUs learning Days (MyCLOUD) project (Wong et al., 2012) in Singapore, and learning by logging with System for Capturing and Reminding of Learning Log (SCROLL) (Ogata et al., 2010) project in Japan. In the context of Thailand, a large-scale educational project named Khon Kaen University (KKU) Smart Learning Academy, shortly called KKU-SLA, has been launched in 2017, and this is on-going project for the improvement of middle school students' learning achievements in English language, mathematics, and science regarding the Programme for International Student Assessment (PISA). The KKU-SLA is a three-year project that aimed to enhance middle school students aged between 13-15 to achieve better learning outcome on their science, mathematics, and reading literacy and also promote their digital literacy and $21^{\text {st }}$ century skills. In addition, the KKU-SLA is trying to find alternative ways to transform and support the teaching and learning of English language, mathematics, and science using digital and hand-held technologies emphasizing mobile devices and applications and ubiquitous learning system. Capital funding was provided by the Thailand government, the Council on Higher Education and Khon Kaen University, and matching funds were also provided by participated secondary schools. The project brings together a group of researchers in many fields from Faculty of Education, Faculty of Engineering, Faculty of Human and Social Sciences, and Faculty of Science at Khon Kaen University working very close with teachers and schools. In the first year of 2017, this project involved 45 secondary schools from four provinces located in northeastern region of Thailand. In 2018, a total of 195 secondary schools from all 19 provinces located in northeastern region of Thailand participated in this project. 
In term of the development of science education, this project aimed to use innovative teaching strategies for mobile and ubiquitous learning for providing middle school students' experience of the new ways of learning in science subject. According to the value of mobile and ubiquitous learning has been shown in a number of research studies as previous mentioned and several research and development project as abovementioned, the science education team is working to transforming traditional middle school science into more meaningful learning with the support of mobile and ubiquitous technology. The learning activities were renovated as an extension of the formal curriculum of middle school general science courses to seamlessly integrate the learning experiences across various dimensions including formal and informal learning contexts, individual and social learning, and physical and digital world. As such, there are five features of transforming Thai traditional middle school science with the support of mobile and ubiquitous technology in the project of KKU Smart Learning Academy as follows.

1) A renovation of school science textbook

2) A renovation of school science laboratory

3) A renovation of school science investigation

4) A renovation of school science homework and assignment

5) A renovation of in-service science teacher professional development programme

According to the renovation of Thai traditional middle school science in this project, mobile and ubiquitous learning approach could be a valuable technology-oriented pedagogical application for leveraging meaningful learning in science and enhancing the learning of conceptual science, both now and in the future.

\section{Conclusion}

Due to the dynamic growth of mobile technology and the spread of the internet, there have created numerous new opportunities for the education of the future and we can expect major changes in education in the next decades. The advancements of mobile technology and wireless communication have brought irreversible changes to how we learn, work, live, and connect. To improve the quality of education in developing countries such as Thailand, new tools must be used both in terms of pedagogical methodology and technical devices, and there is a challenge call for research, development, and implementation of mobile and ubiquitous learning in Thailand. We believe that the notions and concrete examples presented in this paper represent a step forward towards achieving the goal of educational reform and preparing schools and students for a future.

\section{Acknowledgements}

A part of this work was financially supported by the Thailand Research Fund (TRF), the Commission on Higher Education (CHE) and Khon Kaen University (KKU) (Grant no. TRG5780283), and Mahidol University (MU) (Grant no. MRG5980028). Any opinions, findings and conclusions or recommendations expressed in this material are of the authors and do not necessarily reflect the view of the TRF, CHE, KKU, and MU. The author would like to thank Mrs. Krittawaya Thongkoo and Mrs. Narisra Komalawardhana, Ph.D. candidate in Science and Technology Education at Institution for Innovative Learning, Mahidol University, Thailand, Mr. Pawat Chaipidech, Ph.D. 
student in Science Education Program at Faculty of Education, Khon Kaen University, Thailand, and Mr. Komkat Meuansechai and Mr.Kowit Kongphet, current member of Frontiers of Educational Science and Technology (FEST) Research Network, Thailand, for their contribution of previous research works.

\section{References}

Anastopoulou, S., Sharples, M., Ainsworth, S., Crook, C., O’Malley, C., \& Wright, M. (2012). Creating personal meaning through technology-supported science inquiry learning across formal and informal settings. International Journal of Science Education, 34(2), 251-273.

Bernhard, J. (2010). Insightful learning in the laboratory: Some experiences from ten years of designing and using conceptual labs. European Journal of Engineering Education, 35(3), 271-287.

Boyce, C. J., Mishra, C., Halverson, K. L., \& Thomas, A. K. (2014). Getting students outside: Using technology as a way to stimulate engagement. Journal of Science Education and Technology, 23(6), 815-826.

Capaldi, M. (2015). Including inquiry-based learning in a flipped class. PRIMUS, 25(8), 736-744.

Chaipidech, P., \& Srisawasdi, N. (2017). A flipped inquiry-based learning with mobility to improving students' learning performance in science: A comparative study. In Proceedings of the 25th International Conference on Computers in Education (pp. 587-594).

Chu, H. C., Hwang, G. J., \& Tsai, C. C. (2010). A knowledge engineering approach to developing mindtools for context-aware ubiquitous learning. Computers \& Education, 54(1), 289-297.

Ebner, M., \& Holzinger, A. (2007). Successful implementation of user-centered game based learning in higher education: An example from civil engineering. Computers \& Education, 49(3), 873-890.

El-Hussein, M. O. M., \& Cronje, J. C. (2010). Defining mobile learning in the higher education landscape. Educational Technology \& Society, 13(3), 12-21.

Funk, S. (2018). Digital in Southeast Asia \& Thailand 2018. Retrieved from http://mythai.org/digital-southeast-asia-thailand-2018

Hall, T., \& Bannon, L. (2006). Designing ubiquitous computing to enhance children's learning in museums. Journal of Computer Assisted Learning, 22(4), 231-243.

Hofstein, A., \& Lunetta, V. N. (2003). The laboratory in science education: Foundations for the twenty-first century. Science Education, 88(1), 28-54.

Hofstein, A., \& Mamlok-Naaman, R. (2007). The laboratory in science education: The state of the art. Chemistry Education Research and Practice, 8(2), 105-107.

Hung, P. H., Hwang, G. J., Lin, Y. F., Wu, T. H., \& Su, I. H. (2013). Seamless connection between learning and assessment-applying progressive learning tasks in mobile ecology inquiry. Educational Technology \& Society, 16(1), 194-205.

Hung, P. H., Lin, Y. F., \& Hwang, G. J. (2010). Formative assessment design for PDA integrated ecology observation. Educational Technology \& Society, 13(3), 33-42.

Hwang, G.-J. \& Chang, H.-F. (2011). A formative assessment-based mobile learning approach to improving the learning attitudes and achievements of students. Computers \& Education, 56(4), 1023-1031.

Hwang, G.-J., Chu, H.-C., \& Lai, C.-L. (2017). Prepare your own device and determination (PYOD): A successfully promoted mobile learning mode in Taiwan. International Journal of Mobile Learning and Organization, 11(2), 87-107. 
Hwang, G. J., Shi, Y. R., \& Chu, H. C. (2011). A concept map approach to developing collaborative Mindtools for context aware ubiquitous learning. British Journal of Educational Technology, 42(5), 778-789.

Hwang, G.-J., \& Tsai, C.-C. (2011). Research trends in mobile and ubiquitous learning: A review of publications in selected journals from 2001 to 2010. British Journal of Educational Technology, 42(4), E65-E70.

Hwang, G.-J., Tsai, C.-C., \& Yang, S. J. H. (2008). Criteria, strategies and research issues of context-aware ubiquitous learning. Educational Technology \& Society, 11(2), 8191.

Kam, M., Mathur, A., Kumar, A., \& Canny, J. (2009). Designing digital games for rural children: A study of traditional village games in India. In Proceedings of the SIGCHI Conference on Human Factors in Computing Systems (CHI '09) (pp. 31-40). ACM.

Kemp, S. (2018). Digital in 2018: Essential insights into internet, social media, mobile, and ecommence use around the world. We Are Social. Retrieved from https://wearesocial.com/blog/2018/01/global-digital-report-2018

Koehler, M. J., Mishra, P., \& Cain, W. (2013). What is technological pedagogical content knowledge (TPACK)? Journal of Education, 193(3), 13-19.

Komalawardhana, N., \& Panjaburee, P. (2018). Proposal of personalised mobile game from inquiry-based learning activities perspective: Relationships among genders, learning styles, perceptions, and learning interest. International Journal of Mobile Learning and Organisation, 12(1), 55-76.

Kongpet, K., Srisawasdi, N., \& Feungchan, W. (2015). Combining context-aware ubiquitous learning and computer simulation: A lesson learned in elementary science education. In Proceedings of the 23rd International Conference on Computers in Education (pp. 236-243). Hangzhou, China.

Kukulska-Hulme, A., \& Shield, L. (2008). An overview of mobile assisted language learning: From content delivery to supported collaboration and interaction. ReCALL, 20(3), 271-289.

Lai, C.-L., \& Hwang, G.-J. (2015). High school teachers' perspectives on applying different mobile learning strategies to science courses: The national mobile learning program in Taiwan. International Journal of Mobile Learning and Organisation, 9(2), $124-145$.

Laohajaratsang, T. (2010). e-Education in Thailand: Equity, quality and sensitivity for learner and teachers. In Proceedings of the Global Learn Asia Pacific 2010--Global Conference on Learning and Technology (pp. 694-700). Penang, Malaysia.

Laws, P. W., Willis, M.C., \& Sokoloff, D. R. (2015). Workshop physics and related curricula: A 25-year history of collaborative learning enhanced by computer tools for observation and analysis. The Physics Teacher, 53(7), 401-406.

Lawson, A. E. (2000). The generality of hypothetico-deductive reasoning: Making scientific thinking explicit. The American Biology Teacher, 62(7), 482-495.

Looi, C. K., Seow, P., Zhang, B., So, H. J., Chen, W., \& Wong, L. H. (2010). Leveraging mobile technology for sustainable seamless learning: A research agenda. British Journal of Educational Technology, 41(2), 154-169.

Looi, C.-K., Sun, D., Wu, L., Seow, P., Chia, G., Wong, L.-H., Soloway, E., \& Norris, C. (2014). Implementing mobile learning curricula in a grade level: Empirical study of learning effectiveness at scale. Computers \& Education, 77, 101-115.

Love, B., Hodge, A., Corritore, C., \& Ernst, D. C. (2015). Inquiry-based learning and the flipped classroom model. PRIMUS, 25(8), 745-762.

Makaramani, R. (2013). ICT in education country report (Thailand). In Proceedings of theUNESCO Resource Training and Distribution Centre Regional Seminar (pp. 1-11).

McQuiggan, S., Kosturko, L., McQuiggan, J., \& Sabourin, J. (2015). Mobile learning: A handbook for developers, educators, and learners. Hoboken, NJ: John Wiley \& Sons. 
Meuansechai, K., Feungchan, W., \& Srisawasdi, N. (2015). Answer me for learning: Development of ubiquitous learning system for conducting context-aware learning experience. In Proceedings of the 2nd International Conference on Innovations in Education (ICIE2015) (pp. 315-322). Mahidol University, Nakhon Pathom, Thailand.

Milrad, M., Wong, L.-H., Sharples, M., Hwang, G.-J., Looi, C.-K., \& Ogata, H. (2013). Seamless learning: An international perspective on next generation technology enhanced learning. In Z. L. Berge \& L. Y. Muilenburg (Eds.), Handbook of Mobile Learning (pp. 95-108). New York, NY: Routledge.

Ministry of Education. (2015). The Ministry of Education's policy fiscal year 2015. Bangkok: Ministry of Education of Thailand.

Ministry of Education. (2011). Executive summary, information and communication technology (ICT) master plan for education, 2011-2013. Bangkok: Ministry of Education of Thailand.

Ministry of ICT. (2009). The second Thailand information and communication technology (ICT) master plan 2009-2013. Bangkok: Ministry of Information Communications and Technology.

Mishra, P., \& Koehler, M. (2006). Technological pedagogical content knowledge: A framework for teacher knowledge. Teachers College Record, 108(6), 1017-1054.

Nasaro, J., \& Srisawasdi, N. (2014). Students' self-efficacy and acceptance toward context-aware ubiquitous learning in biology education: A case of photosynthesis in plant. In Proceedings of the 22nd International Conference on Computers in Education (pp. 413-420). Nara, Japan.

National Research Council (NRC). (1996). The national science education standards. Washington, DC: National Academy Press.

National Research Council (NRC). (2000). Inquiry and the national science education standards: A guide for teaching and learning. Washington, DC: National Academy Press.

Ogata, H., Li, M., Bin, H., Uosaki, N., Moushir, M. E.-B., \& Yano, Y. (2010). SCROLL: Supporting to share and reuse ubiquitous learning log in the context of language learning. Research and Practice in Technology Enhanced Learning, 6(2), 69-82.

OECD/UNESCO (2016). Education in Thailand: An OECD/UNESCO perspective. Paris: OECD and United Nations Educational, Scientific, and Cultural Organization, OECD Publishing. $\quad$ Retrieved http://unesdoc.unesco.org/images/0024/002457/245735e.pdf

Raes, A., Schellens, T., De Wever, B., \& Vanderhoven, E. (2012). Scaffolding information problem solving in web-based collaborative inquiry learning. Computers \& Education, 59(1), 82-94.

Rogers, Y., Price, S., Randell, C., Fraser, D. S., Weal, M., \& Fitzpatrick, G. (2005). Ubilearning integrating indoor and outdoor learning experiences. Communications of the ACM, 48(1), 55-59.

Serrano-Cámara, L., Paredes-Velasco, M., Alcover, C., \& Velazquez-Iturbide, J. (2014). An evaluation of students' motivation in computer-supported collaborative learning of programming concepts. Computers in Human Behavior, 31, 499-508.

Sokoloff, D. R., Laws, P. W., \& Thornton, R. K. (2007). RealTime physics: Active learning labs transforming the introductory laboratory. European Journal of Physics, 28(3), S83-S94.

Sollervall, H., Gil de la Iglesia, D., Milrad, M., Peng, A., Pettersson, O., Salavati, S., \& Yau, J. (2011). Trade-offs between didactical and technological design requirements affecting the robustness of a mobile learning activity. In Proceedings of the 19th International Conference on Computers in Education (ICCE 2011).

Srisawasdi, N. (2012). Student teachers' perceptions of computerized laboratory practice 
for science teaching: A comparative analysis. Procedia-Social and Behavioural Sciences, 46, 4031-4038.

Srisawasdi, N. (2015). Evaluation of motivational impact of a computer-based nanotechnology inquiry learning module on the gender gap. Journal of Nano Education, 7(1), 28-37.

Srisawasdi, N., Kongpet, K., Muensechai, K., Feungchan, W., \& Panjaburee, P. (2016). The study on integrating visualized simulation into context-aware ubiquitous learning activities for elementary science education. International Journal of Mobile Learning and Organization, 10(4), 263-291.

Srisawasdi, N., \& Kroothkeaw, S. (2014). Supporting students' conceptual learning and retention of light refraction concepts by simulation-based inquiry with dual-situated learning model. Journal of Computers in Education, 1(1), 49-79.

Srisawasdi, N., \& Panjaburee, P. (2015). Exploring effectiveness of simulation-based inquiry learning in science with integration of formative assessment. Journal of Computers in Education, 2(3), 323-352.

Srisawasdi, N., \& Panjaburee, P. (2016). Emerging pedagogies for computer-based learning. Journal of Computers in Education, 3(3), 247-251.

Srisawasdi, N., Pondee, P., \& Bunterm, T. (2018). Preparing pre-service teachers to integrate mobile technology into science laboratory learning: An evaluation of technology-integrated pedagogy module. International Journal of Mobile Learning and Organization, 12(1), 1-17.

Srisawasdi, N., \& Sornkhatha, P. (2014). The effect of simulation-based inquiry on students' conceptual learning and its potential applications in mobile learning. International Journal of Mobile Learning and Organisation, 8(1), 28-49.

Thongkoo, K., Panjaburee, P., \& Daungcharone, K. (2017). An inquiry blended SECI model-based learning support approach for promoting perceptions and learning achievement of university students. In Proceedings of the 6th IIAI International Congress on Advanced Applied Informatics (IIAI-AAI) (pp. 527-532).

Thornton, R. K., \& Sokoloff, D. R. (1998). Assessing student learning of Newton's laws: The force and motion conceptual evaluation and the evaluation of active learning laboratory and lecture curricula. American Journal of Physics, 66(4), 338-352.

Tobin, K. (1990). Research on science laboratory activities in pursuit of better questions and answers to improve learning. School Science and Mathematics, 90(5), 403-418.

Tsai, C.-W., Shen, P.-D., Tsai, M.-C., \& Chen, W.-Y. (2016). Exploring the effects of web-mediated computational thinking on developing students' computing skills in a ubiquitous learning environment. Interactive Learning Environments, 25(6), 762-777.

Uemukai, T., Hara, T., \& Nishio, S. (2004). A method for selecting output data from ubiquitous terminals in a ubiquitous computing environment. In Proceedings of the 24th International Conference on Distributed Computing Systems Workshops (pp. 562-567).

Valderrama Bahamóndez, E. C., \& Schmidt, A. (2011). Mobile phones, developing countries and learning. In W. Ng (Ed.), Mobile Technologies and Handheld Devices for Ubiquitous Learning: Research and Pedagogy (pp. 120-137). Hershey, PA: Information Science Reference.

Wong, L.-H., Chai, C.-S., Chin, C.-K., Hsieh, Y.-F., \& Liu, M. (2012). Towards a seamless language learning framework mediated by the ubiquitous technology. International Journal on Mobile Learning and Organisation, 6(2), 156-171.

Wu, P.-H., Hwang, G.-J., Tsai, C.-C., Chen, Y.-C., \& Huang, Y.-M. (2011). A pilot study on conducting mobile learning activities for clinical nursing courses based on the repertory grid approach. Nurse Education Today 31(8), e8-e15.

Yang, S. J. H. (2006). Context aware ubiquitous learning environments for peer-to-peer collaborative learning. Educational Technology \& Society, 9(1), 188-201. 